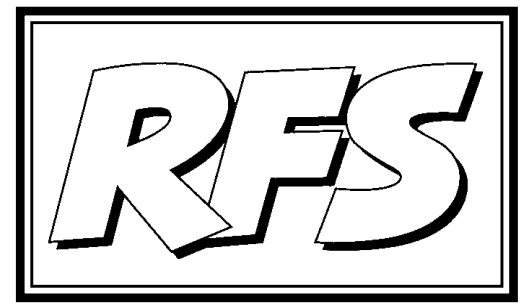

Revista de Fomento Social, 60 (2005), 623-641

\title{
Cómo ayudar a los países pobres ${ }^{1}$
}

Nancy BIRDSALL, Dani RODRIK y Arvind SUBRAMANIAN ${ }^{2}$

(PaLABRAS ClaVE: DeSARROLlo, Países POBRES, Ayuda INTERNACIONAL, LIBERALIZACIÓN COMERCIAL.

KEY WORDS: DEVELOPMENT, POOR COUNTRIES, INTERNATIONAL AID, TRADE LIBERALIZATION)

1 Artículo aparecido en la revista Foreign Affairs, vol. 84, n.4, august 2005. La Revista de Fomento Social ha obtenido los derechos para su publicación en castellano. Agradecemos a Foreign Affairs su autorización. Versión castellana de José J. Romero Rodríguez. Mantenemos las alusiones temporales como aparecen en el texto original.

2 NANCY BIRDSALl es Presidente del Center for Global Development de Washington;D. C. DANI RodRIK es Profesor de International Political Economy en la John F. Kennedy School of Government de Harvard; Arvind Subramanian es Jefe de división en el Departamento de Investigación del Fondo Monetario Internacional. Los puntos de vista expresados aquí lo son a título personal y no representan a sus respectivas instituciones. 
2005 se ha convertido en el año del desarrollo. En septiembre, en la Cumbre del Milenio de Jefes de Estado de Naciones Unidas, en Nueva York, los líderes de los países ricos subrayarán su compromiso con un más profundo alivio de la deuda y un incremento de los programas de ayuda a los países en desarrollo. Los Objetivos de Desarrollo del Milenio, pieza central del programa de la conferencia, hacen una llamada para disminuir a la mitad los niveles de pobreza y hambre en el mundo en el horizonte 2015.

La cumbre se centrará en aumentar la ayuda internacional al $0,7 \%$ del PNB de los países donantes con el fin de poder financiar la duplicación que tendrán las transferencias de ayuda a las áreas especialmente necesitadas, en particular en África. En relación con el comercio global, los esfuerzos se centrarán en la Ronda Doha de negociaciones comerciales multilaterales y en la apertura de los mercados a importantes exportaciones (tales como el algodón) provenientes de los países en desarrollo. De modo que las discusiones estarán basadas en dos supuestos subyacentes implícitos, pero críticos: que los países ricos pueden configurar el desarrollo en el mundo pobre y que sus esfuerzos para conseguirlo deberían consistir principalmente en proporcionar recursos y oportunidades de mercado a los países pobres.

Estos supuestos ignoran lecciones clave de las últimas cuatro décadas-y de la historia económica, más en general-. El desarrollo es algo que viene mayormente determinado por los propios países pobres, y los de fuera sólo pueden jugar un papel limitado. Los propios países en desarrollo ponen énfasis en este punto, pero en los países ricos se olvida frecuentemente. Al igual que el hecho de la ayuda financiera y una mayor apertura de los mercados de los países ricos son herramientas que sólo tienen una capacidad limitada para disparar el crecimiento, especialmente en los países más pobres. La enorme cantidad de energía y de capital político gastado en estos esfuerzos en los círculos oficiales amenaza con desviar nuestra atención de otras formas en que los países ricos puede hacer menos daño y más bien. Una atención singular sobre la ayuda y el acceso a los mercados en la Cumbre del Milenio de septiembre 2005 no debería arrinconar otras medidas potencialmente provechosas. 


\section{Botones de muestra ${ }^{3}$}

Consideremos Nicaragua y Vietnam. Ambos son países pobres con economías predominantemente agrarias. Ambos han padecido largos periodos de conflicto. Y ambos se han beneficiado de una ayuda externa sustancial. Pero sólo Vietnam ha reducido su pobreza espectacularmente y ha disfrutado de un rápido crecimiento económico (5\% per capita desde 1988). Nicaragua ha logrado apenas mantenerse a flote económicamente, con un crecimiento per capita demasiado modesto como para lograr que se acorte, aunque sea un un poco, la lista de los países pobres.

Vietnam se enfrentó al embargo de los EEUU hasta 1994, y todavía no es miembro de la Organización Mundial del Comercio (OMC). A pesar de estos obstáculos, ha encontrado mercados para sus crecientes exportaciones de café y de otros productos agrarios y ha comenzando también a diversificar con éxito su producción en el sector de las manufacturas, especialmente las textiles. Nicaragua, por el contrario, se beneficia del acceso preferencial al lucrativo mercado estadounidense y ha conseguido borrar de su deuda oficial varios miles de millones de dólares en los años 90. Aun así, su café y sus industrias de prendas de vestir no han sido capaces de competir con los de Vietnam.

¿Por qué Vietnam ha superado a Nicaragua? Las respuestas son internas: la historia y las instituciones económicas y políticas han ganado la partida a otros factores a la hora de determinar el éxito económico. El acceso al mercado de EEUU y la generosidad de los donantes occidentales no han sido bastante potentes para superar la historia nicaragüense de desigualdad social y económica: en este país, la tierra y el poder han estado desde hace mucho tiempo en manos de unas pocas élites, y el gobierno no ha sido capaz de invertir lo suficiente en infraestructuras y en servicios públicos de bienestar.

Las experiencias de muchos otros países en desarrollo confirman la importancia de factores internos específicos. Al igual que Vietnam, China y la India -las dos emergentes "super-estrellas" del último cuarto de siglo- no se han beneficiado de preferencias comerciales. Y ni una ni otra ha recibido mucha ayuda externa, si se compara con los países de África y de Centroamérica. Pero promoviendo reformas domésticas creativas, China e India han prosperado, y en ambos países la pobreza se ha reducido sensiblemente.

3 Nota del traductor. Los autores titulan: "Bootstraps". Traducimos libremente. 
En el lado opuesto, muchos países africanos han sido incapaces de emular el éxito de Vietnam, a pesar de no ser ni más pobres ni más agrarios. Ciertamente, los indicadores de salud y educación han mejorado notablemente en África, y algunos de sus países han logrado una estabilidad macroeconómica. Pero aun en el caso de los países con mejores resultados, el crecimiento y la productividad siguen siendo modestos, y la inversión depende completamente de las "infusiones" de ayuda externa. Podría ser tentador atribuir los escasos éxitos africanos - Botswana y Mauricio, por ejemplo- a la alta demanda exterior de sus exportaciones (diamantes y prendas de vestir, respectivamente), pero esa explicación no va mucho más lejos. Obviamente, ambos países serían considerablemente más pobres sin el acceso a los mercados exteriores. Pero lo que les distingue no son las ventajas externas de que disfrutan, sino su habilidad para explotar esas ventajas. Con frecuencia, las dotaciones en recursos naturales han hecho daño a muchos países en desarrollo: la palabra "diamante" difícilmente evoca la imagen de paz y prosperidad en Sierra Leona, y el petróleo ha sido más una maldición que una bendición para Angola, Guinea Ecuatorial, Nigeria, y muchos otros.

Observemos el caso de México. Tiene la ventaja de compartir una frontera de 2.000 millas con el mayor poder económico del mundo. Desde que el Acuerdo Norteamericano de Libre Comercio entró en vigor en 1994, los EEUU han concedido el acceso libre de aranceles a sus mercados a los bienes mexicanos, han realizado enormes inversiones en la economía mexicana, y han seguido absorbiendo a millones de trabajadores mexicanos. Durante la crisis del peso de 1994-1995, el Tesoro de los EEUU incluso subvencionó la estabilidad financiera de México. La ayuda económica externa no lo hace mucho mejor. Pero desde 1992 la economía de México ha crecido a una tasa media anual de apenas $1 \%$ per capita. Esta cifra es muy inferior a las tasas del crecimiento de las super-estrellas de Asia. Y es sólo una fracción del crecimiento del propio México del 3,6\% al año en las décadas que precedieron a su crisis de la deuda de 1982. El acceso a los mercados y a los recursos externos no ha sido capaz de compensar los problemas internos de México.

Una excepción notable a las limitaciones de la ayuda exterior es la pertenencia a la Unión Europea. Ofreciendo a sus vecinos del Este y del Sur no sólo ayudas financieras y acceso a mercados sino la perspectiva de entrar en la Unión, la UE ha estimulado profundos cambios políticos e institucionales y un crecimiento impresionante en unos 20 países. Pero la excepción prueba la regla: la UE no es simplemente un acuerdo económico; es también un sis- 
tema político en el que los Estados miembros transfieren amplios poderes legislativos a la autoridad central. A cambio, el centro carga con significativas responsabilidades para el bienestar económico de cada miembro.

Por desgracia, la adhesión a la UE o a algún otro gran poder no es una opción para la mayoría de las partes pobres del mundo y el aumento de los recursos financieros y de las oportunidades comerciales para los países más pobres no es un sustituto suficiente.

\section{Acceso fácil}

Para empezar, está la cuestión del acceso a los mercados. Actualmente el sistema de comercio internacional estálleno de inequidades. Los países ricos fijan sus aranceles más altos a las importaciones importantes procedentes de los países en desarrollo -prendas de vestir y agricultura, por ejemplo. Los aranceles aumentan conforme aumenta el grado de procesamiento de los productos, desincentivando la industrialización en los países pobres. Además, las negociaciones comerciales multilaterales carecen de transparencia y con frecuencia excluyen a los países en desarrollo de la misma posibilidad de negociar. Utilizar los procedimientos de la OMC para resolver las disputas comerciales exige dinero y pericia técnica, de los que carecen los países pobres.

Pero decir que estos defectos obstaculizan el desarrollo en economías con dificultades sería saltarse el notable éxito en las últimas dos décadas de Vietnam y China en la exportación de bienes manufacturados, de Chile en la exportación de vino y salmón, y más recientemente de la India en la "exportación" de servicios. Estos países han conseguido éxitos en la exportación, a pesar de los impedimentos. Y las barreras sobre las exportaciones de manufacturas provenientes de los países en desarrollo eran aún más altas cuando los "tigres" asiáticos llegaron a la escena, en los años 60 y 70.

Muchos argumentan que los aranceles agrícolas en particular representan un impedimento para el crecimiento económico de los países pobres. El Banco Mundial y organizaciones como OXFAM argumentan que eliminando los subsidios agrícolas y el proteccionismo en los países industrializados se reduciría significativamente la pobreza en el mundo en desarrollo. Las vacas europeas, el famoso ejemplo que siempre se pone, son más ricas -porque reciben 2,50\$ diarios en subsidios- que un tercio de la población mundial. 
Y sin embargo es una realidad que la liberalización del comercio agrario beneficiaría grandemente a los consumidores y contribuyentes de los países ricos. ¿Por qué? Porque los subsidios agrícolas sirven primero y principalmente para transferir recursos de los consumidores y contribuyentes a los agricultores dentro del mismo país. Así, los ciudadanos de los países desarrollados obtendrían la mayor parte de los beneficios del recorte de esos subsidios. Otros países se ven afectados solamente en la medida en que los precios mundiales suban. Pero los grandes ganadores, los claros ganadores de tales aumentos de precio sería los países que son grandes exportadores netos de productos agrícolas -países ricos, como los EEUU, países de renta media, como Argentina, Brasil y Thailandia.

¿Y qué pasa con los países más pobres? Por un lado, muchos países pobres son actualmente importadores netos de productos agrarios, por lo que se benefician de los bajos precios mundiales. Un aumento en los precios podrá ayudar a los pobres del mundo rural, que venden bienes agrícolas, pero empeorarían la situación de los pobres de los medios urbanos, los consumidores. La pobreza neta podría ser reducida, pero hasta qué punto, depende de manera complicada de las condiciones de las carreteras y de los mercados de fertilizantes y otros insumos, de qué parte de la ganancia sea capturada por los agricultores pobres frente a los intermediarios, y en el perfil de la pobreza de cada país.

Independientemente de si la liberalización agrícola aumenta o disminuye la pobreza, el impacto no sería significativo. La mayoría de los estudios predicen que el efecto de tal liberalización sobre los precios mundiales sería pequeño. El Fondo Monetario Internacional (FMI) estima que los precios mundiales subirían solamente entre un 2 y un $8 \%$ para el arroz, el azúcar y el trigo; un $4 \%$ en el caso del algodón; y $7 \%$ para la carne de vacuno. La variación típica anual de los precios mundiales de estas materias primas es, por lo menos, de un orden de magnitud mayor.

Tomemos el caso específico del algodón. Las estimaciones más creíbles aseguran que el impacto de la total eliminación de los subsidios de EEUU al algodón sobre los precios mundiales sería menor del 15\%. ¿Qué efecto tendría ello en las rentas de los agricultores de África Occidental? Existe de hecho un punto de referencia para comparar. En 1994, los estados miembros de la zona monetaria de la Comunidad Financiera Africana (en la que 14 países africanos han tenido sus monedas vinculadas al franco francés desde 1948) devaluaron su moneda de 50 a 100 CFA por franco francés, doblando 
efectivamente el precio doméstico de las exportaciones de algodón. Si al menos alguna de las ganancias de precio resultantes hubieran ido a parar a los productores de algodón (y no a los intermediarios o a la inflación), la renta de los agricultores se hubiera incrementado en países como Burkina Faso y Benin. En realidad la subida del precio hubiera aumentado la renta y disminuido la pobreza aún más de lo que hubiera conseguido la eliminación de los subsidios norteamericanos al algodón. Sin embargo, hay poca evidencia de que se haya producido una significativa reducción de la pobreza rural. Un estudio del Banco Mundial demostró que la pobreza en Burkina Faso siguió siendo pertinazmente alta e incluso aumentó en algunas regiones del país.

Además, una reducción general de las barreras al comercio en los países ricos podrían empeorar la situación de algunos de los países más pobres del mundo. Una parte sustancial de las exportaciones de los países menos desarrollados disfrutan de condiciones favorables de acceso a los mercados de los países ricos bajo diversos tipos de acuerdos comerciales preferenciales. Por ejemplo, al acabarse en enero de 2005 el viejo sistema de cuotas sobre la ropa, países pobres como Bangladesh, Cambodia y Lesotho, que se beneficiaban de acuerdos preferenciales, tienen un miedo justificado de la competencia de China y Vietnam. Las pérdidas de acceso preferencial para los países más pobres no es una justificación para detener el tren de la liberalización del comercio. Pero es un motivo adicional para ser precavidos a la hora de estimar la magnitud de las ganancias de los países pobres como resultado de una agenda centrada en el comercio.

Por supuesto, si el comercio global y el crecimiento se hundieran, como ocurrió en el periodo entre las guerras mundiales, el desarrollo internacional recibiría un duro golpe. Un próspero sistema comercial multilateral es importante para mantener alejada esa posibilidad, y puede proteger a los países más pobres de presiones bilaterales inaceptables. Un éxito en la Ronda Doha podría estimular el comercio entre los países en desarrollo y sería la señal de una voluntad política por parte de la comunidad internacional para mantener el sistema en funcionamiento y prevenir una implosión -aun en el caso de que las ganancias efectivas de las reducciones de las barreras al comercio para los países más pobres fueran modestas.

\section{3. ¿Más dinero?}

Ya que no basta con un mejor acceso a los mercados ¿qué tal si se aumenta la ayuda? Aumentar la ayuda a los países más pobres del mundo es una 
recomendación central de los recientes informes del Proyecto Desarrollo del Milenio de Naciones Unidas y de la comisión sobre África del primer ministro británico Tony Blair, y, junto con menor corrupción y mejor gestión en los países pobres, es una piedra angular de la estrategia imaginada para conseguir los Objetivos de Desarrollo del Milenio.

La ayuda ha conseguido algunas cosas muy importantes. En el frente de la sanidad, la viruela ha sido erradicada, las tasas de mortalidad infantil han disminuido, y enfermedades tales como la diarrea y "la ceguera del río" han sido extensamente tratadas. Los programas de ayuda han mejorado el acceso de las mujeres a modernos sistemas contraceptivos en Bangladesh y Egipto y ha ayudado a aumentar la escolarización en Uganda y Burkina Faso. La ayuda ha permitido en gran parte financiar el (todavía limitado) acceso a medicinas contra el SIDA en los países pobres. En la última década, la ayuda ha permitido restaurar la paz y el orden después de conflictos en lugares tales como Bosnia, Timor Oriental, y Sierra Leona. Además, la ayuda puede ser un vehículo para el asesoramiento político y el diálogo entre receptores y extranjeros. Se han dado éxitos macroeconómicos, tales como la subvención de mil millones de dólares que permitió a Polonia establecer un fondo de estabilización del tipo de cambio en 1990. Al estabilizar la moneda polaca, ésta relativamente pequeña cantidad de financiación proporcionó un valioso respiro para la implementación de más amplias reformas políticas.

Lo que todos estos éxitos tienen en común es que estaban estrechamente enfocados hacia objetivos específicos. La ayuda funciona bien, pero sólo cuando los países receptores hacen las cosas correctas para ayudarse a sí mismos y tienen la capacidad y el liderazgo para gastar el dinero prudentemente. Algunas evidencias estadísticas indican que existe un vínculo entre la ayuda financiera y el crecimiento. Pero la ayuda no ha estado asociada con incrementos sostenidos de productividad y de salarios que es lo que a fin de cuentas importa. Durante la década de los 90, por ejemplo, algunos países de África subsahariana recibieron fondos que ascendieron por término medio a alrededor del $12 \%$ de su PNB, mientras que su tasa de crecimiento per capita bajo un $0,6 \%$ al año. Mientras tanto, algunos de los actuales éxitos de desarrollo -como Chile y Malasia- dependieron poco de la ayuda. Y la ayuda a China e India ha sido muy pequeña.

Existen muchas razones que explican el rendimiento ambivalente de la ayuda externa. Los propios donantes causan muchos de los problemas. Los países receptores pueden verse abrumados por la multiplicidad de donantes 
que persiguen muchos y, a menudo, inconsistentes objetivos, desembolsando ayuda para innumerables proyectos eimponiendo una plétora de condiciones para su uso. Estos factores contribuyen a aumentar la falta de capacidad institucional de un país pobre más que a contrarrestarla. Y, por encima de esto, está la natural volatilidad e incertidumbre de la ayuda exterior, que hace difícil a los países receptores el planificar sus presupuestos. Durante más de una década, las burocracias de los estados y organizaciones donantes, no han sido capaces, a pesar de las buenas intenciones y de las constantes resoluciones, de cambiar los incentivos y restricciones políticas que impiden la reforma de sus aparatos de reparto de ayuda.

Sin embargo, probablemente resultan más importantes las deficiencias institucionales por el lado del receptor. La ayuda sólo es tan buena como lo sea la capacidad de una economía y de un gobierno receptor de usarla prudente y productivamente. Así, el dilema fundamental es el siguiente: los países que más necesitan la ayuda suelen ser aquellos menos capaces de usarla bien. Eso pone límites a la magnitud con que las grandes inyecciones de fondos externos pueden marcar la diferencia.

El mayor ejemplo de éxito de la ayuda -el Plan Marshall-ilustra la importancia de la competencia institucional doméstica. Precisamente porque las instituciones y capacidades del Reino Unido, Francia y Alemania sobrevivieron en gran medida a la guerra, incluso sus economías arrasadas por la guerra fueron capaces de explotar por completo el potencial de la asistencia financiera.

Esta sencilla cuestión destaca el punto de vista de que la ayuda es una condición sine qua non para el desarrollo de África a causa de la mala geografía del continentey de su entorno favorable para las enfermedades. El crecimiento de un país puede de hecho verse obstaculizado por su inadecuación para la agricultura, su aislamiento geográfico, y su susceptibilidad hacia la malaria y otras enfermedades tropicales. En tales casos, puede parecer apropiado que los países concedan mayor ayuda. Pero la geografía adversa no altera fundamentalmente el hecho de que la efectividad de la ayuda depende de las instituciones del país receptor. En el mejor de los casos, la financiación externa ha permitido la reconstrucción de los países después de conflictos y les ha ayudado a conseguir algunos objetivos específicos, pero su rol en la creación y el sostenimiento de las instituciones clave y de la salud económica a largo plazo ha sido mucho menos claro. 


\section{Pecados de comisión}

Para ayudar a los países en desarrollo a que se ayuden a sí mismo, las naciones ricas deben empezar por eliminar las cargas que imponen a los pobres. Actualmente, el mundo desarrollado utiliza los acuerdos comerciales internacionales para imponer costosas y onerosas obligaciones a los países pobres. El ejemplo más egregio ha sido el acuerdo sobre la propiedad intelectual de la OMC, el llamado ADPIC (Acuerdo sobre los Aspectos de los Derechos de Propiedad Intelectual relacionados con el Comercio $)^{4}$. A pesar de los esfuerzos recientes para amortiguar su impacto en los países más pobres, el ADPIC hará que los precios de medicamentos esenciales sean significativamente más caros, y esto precisamente en un momento en que los países pobres están siendo devastados por una de las peores epidemias nunca conocidas - el HIV-SIDA-. El aumento del precio significa que ese dinero de los ciudadanos de los países pobres será transferido directamente a las ricas compañías farmacéuticas. Los ingresos resultantes, aunque representan una cantidad importante de dinero para los países pobres, sólo será una parte relativamente pequeña de los beneficios netos totales de esas empresas -apenas lo suficiente para inducir una inversión extra en investigación y desarrollo.

Una comunidad internacional que impone el ADPIC y otros acuerdos similares pierde el derecho a cualquier pretensión de comportarse de forma favorable al desarrollo. Esto tiene que cambiar: los países ricos no pueden simplemente corregir el ADPIC; deben abolirlo del todo. Una simple comparación lo deja bien claro: algunos de los principales países industriales como Italia, Japón y Suiza adoptaron la protección de patentes farmacéuticas cuando su renta per cápita era de alrededor 20.000 ; los países en desarrollo lo adoptarán a unos niveles de 500 \$ per cápita, en el caso de los más pobres, y de 2.000 a $4.000 \$$ en el de los países de renta media. Según este criterio, obligar a los países en desarrollo a soportar el ADPIC resulta de 50 a 100 años prematuro.

Pero las obligaciones gravosas no se reducen al ADPIC. Los acuerdos comerciales entre EEUU y países como Jordania, Marruecos y Vietnam les han exigido a estos últimos que se adhieran a regulaciones sobre propiedad intelectual que van más allá del ADPIC, aumentando aún más el monopolio

4 Nota del traductor: más conocido por las siglas en inglés TRIPS (Trade-Related Aspects of Intellectual Property Rights). 
de los titulares de las patentes y restrigiéndoles el acceso a los medicamentos. Otros acuerdos comerciales han exigido a los países en desarrollo que abrieran inmediatamente sus mercados de capital, a pesar de las recientes experiencias que demuestran que al hacerlo exponen a los países a la volatilidad de los flujos internacionales de capital.

Igualmente crucial para el empoderamiento de los países pobres es el proporcionarles espacio suficiente para que construyan su propia política económica. Durante la última década, los economistas han terminado por comprender que el desarrollo económico es al mismo tiempo más fácil y más duro de lo que se pensaba con anterioridad. Muchos países han reducido la pobreza y han generado un crecimiento económico significativo sin necesidad de las profundas y exhaustivas reformas que han sido la pieza central para las instituciones de desarrollo durante el último cuarto de siglo. Esta es la buena noticia. La mala noticia es que hay pocas pautas generales de política económica que parezcan aplicarse a todos los países -excepto para algunos principios básicos como la estabilidad macroeconómica, apertura hacia el exterior, gobierno responsable, e incentivos basados en el mercado. La parte más difícil consiste en avanzar más allá de estos vastos objetivos y descubrir cuáles son las políticas específicas apropiadas para las necesidades particulares de cada país en desarrollo. Los numerosos países pobres que han progresado en cuanto a esos criterios generales pueden orientar mejor su propia ruta económica si tienen el espacio adecuado para la autonomía y la experimentación política. La idea puede sonar radical, pero ¿le habría ido mejor a China si hubiera aplicado en 1978 un rutinario programa de ajuste estructural del Banco Mundial en vez de un heterodoxo gradualismo de su propia cosecha?

Casi todos los casos de éxito en materia de desarrollo de los últimos 50 años han estado basados en innovaciones políticas creativas $-\mathrm{y}$, con frecuencia, heterodoxas. Por ejemplo, Corea del Sur y Taiwan, combinaron sus orientaciones hacia el comercio exterior con políticas heterodoxas: subsidios a la exportación, créditos a sectores prioritarios, infracciones a los derechos de autor y a las patentes, exigencias de contenido doméstico para la producción local, altos niveles de barreras arancelarias y no arancelarias, propiedad pública de amplios segmentos de la banca y de la industria, y restricciones a los flujos de capital, incluidos las inversiones extranjeras directas. Desde finales de los años 70, China ha seguido también un estrategia altamente heterodoxa de doble vía, saltándose prácticamente todas las reglas del libro -incluyendo, muy notoriamente, la salvaguarda de los 
derechos de propiedad privada. La India, que elevó su tasa de crecimiento económico en los primeros años 80 , siguió siendo una economía altamente protegida en los años 90 . Incluso Chile -destacado aparentemente heterodoxo de América Latina que consiguió lograr al mismo tiempo crecimiento y democracia- violó la sabiduría convencional al subvencionar sus nacientes industrias de exportación y gravar los flujos de entrada de capital.

Por el contrario, les ha ido menos bien a países que se han ajustado más estrictamente a la ortodoxa agenda de la reforma estructural -muy especialmente en América Latina. Desde mediados de los 80, prácticamente todos los países de América Latina han abierto y desregulado sus economías, han privatizado sus empresas públicas y han permitido el acceso sin restricciones del capital exterior. Sin embargo han crecido apenas una fracción de la de los reformadores heterodoxos y han sido fuertemente golpeados por la inestabilidad macroeconómica.

Las experiencias comparadas de Asia oriental, China e India sugieren que el secreto del crecimiento con reducción de la pobreza reside en la creación de oportunidades de negocio para los inversores nacionales, incluidos los pobres, mediante innovaciones institucionales talladas a la medida de las realidades políticas e institucionales locales. Ignorar esas realidades tiene el peligro de que las políticas en favor de los pobres, aun cuando formen parte de programas aparentemente sólidos y bien intencionados del Fondo Monetario Internacional (FMI) y del Banco Mundial, sean capturadas por las élites locales.

Por eso, los países ricos y las organizaciones internacionales de desarrollo no deberían actuar como si las políticas y los arreglos institucionales adecuados fueran iguales a través del espacio y del tiempo. Mejor aún, las reglas actuales de la OMC sobre los subsidios, la inversión extranjera y las patentes descartan algunas de las opciones políticas tomadas, por ejemplo, por Corea del Sur y Taiwan en el pasado, cuando las reglas impuestas por el GATT (General Agreement of Tariffs and Trade), predecesor de la OMC, eran más permisivas. Más aún, a los nuevos miembros de la OMC se les exige que conformen sus políticas comerciales e industriales a criterios que van mucho más allá de los que existen en los acuerdos de la OMC. Los nuevos estándares bancarios del acuerdo de Basilea II, más apropiado para los bancos de los países industrializados, tienen el peligro de hacer que les sea más difícil competir a los bancos de los países en desarrollo.

Desde luego, no toda disciplina económica internacional impuesta es da- 
ñina. El principio de transparencia, consagrado en los acuerdos comerciales internacionales y en muchos códigos financieros globales, es plenamente consistente con la independencia política, siempre y cuando los gobiernos dispongan de carta blanca a la hora de definir los contenidos concretos de sus políticas. Un sistema económico internacional que funcione bien no necesita reglas. Pero las reglas internacionales deberían regular la conexión entre diferentes políticas y regímenes institucionales, y no borrarlos.

Hay señales de cambio en la actitud del mundo rico. Algunos donantes, especialmente el Reino Unido y EEUU, este último con su "Cuenta del Reto del Milenio" ${ }^{5}$, se están distanciando de la política que consistía en fijar condiciones explícitas y onerosas para sus donaciones y préstamos y, en su lugar, investigan de antemano a los solicitantes para asegurarse de que la ayuda será razonablemente bien gastada. El Banco Mundial y otras organizaciones están diseñando programas con países en los que los recursos se desembolsan no a cambio de reforma política sino sobre la base de criterios definidos de progreso acordados previamente-ya sea una inflación reducida-, o auditorías externas más exhaustivas de las cuentas del gobierno. Estos cambios merecen ser apoyados.

Los países ricos hacen daño también a sus contrapartes en desarrollo de otras formas, muy notoriamente con sus emisiones de gases de efecto invernadero. Según un consenso científico creciente, los costos del cambio climático recaerán desproporcionadamente sobre los países en desarrollo. Las estimaciones de estos costos, incluyendo la reducción en la disponibilidad de agua y en la productividad agrícola, varían entre el 4 y el $22 \%$ de la renta de los países pobres. Los países ricos deben adelantarse en promulgar medidas que vayan más allá del Protocolo de Kyoto. Un sistema de derechos de emisión negociables, basado en el mercado, ofrece la gran oportunidad de combinar la eficiencia con un tratamiento equitativo a los países en desarrollo. A las naciones pobres se les asignarían las emisiones suficientes para asegurar su crecimiento futuro -el mismo derecho del que han disfrutado durante siglos los países industrializados-. Estos intercambios basados en el mercado garantizarían que la contaminación bajaría allí donde los costes sean más bajos, asegurando la máxima eficiencia: si los costes son menores en la India que en los EEUU, por ejemplo, los EEUU deberían pagar a la India por contaminar menos, y a la India le iría financieramente mejor haciéndolo así.

5 Nota del traductor: "Millennium Challenge Account": nuevo programa de ayuda de EEUU. 


\section{Pasos positivos}

Los países ricos pueden también dar pasos positivos para beneficiar directamente a los países en desarrollo -concretamente, actuando contra los líderes corruptos, ayudando la investigación y el desarrollo e incrementando la movilidad laboral global-.

El reto más serio para los países de las zonas más pobres del mundo, especialmente África, es la gobernanza. El continente africano ha sido devastado tanto por conflictos y guerras civiles como por líderes voraces que han saqueado las riquezas naturales de sus países. Podría decirse que los gobernantes corruptos y sus débiles regímenes han sido con mucho el lastre más importante que ha padecido el desarrollo africano. La situación podría empezar a mejorar si se incrementa la democratización. Y los países ricos pueden jugar un gran papel en el proceso de reforma, por la sencilla razón de que la corrupción tiene dos lados: la oferta y la demanda. Por cada líder que exige un soborno, hay normalmente una empresa multinacional o un funcionario occidental que se ofrece a pagarlo. Por cada fortuna procedente de enriquecimiento ilícito, hay habitualmente una institución financiera europea o norteamericana que proporciona un paraíso para el botín. Los gobiernos de los países ricos tienen que dar pasos para bloquear estas actividades.

Se han dado pasos notables en la buena dirección: el Departamento Británico para el Desarrollo Internacional ayudó a poner en marcha hace unos pocos años la "Iniciativa por la Transparencia de las Industrias Extractivas", y las Naciones Unidas y la OCDE han trabajado conjuntamente para atajar los sobornos de los funcionarios en los países en desarrollo por parte de los extranjeros. Pero estos esfuerzos no han ido lo suficientemente lejos.

Muchas instituciones, por ejemplo, la OCDE y el gobierno de los EEUU, tienen leyes contra el soborno de funcionarios extranjeros. Pero esas normas son con frecuencia de alcance limitado y débiles en su aplicación. Por ejemplo, una laguna jurídica en las leyes estadounidenses ("los donativos aplazados") invita al abuso. Algunas reglas de la OCDE dañan la transparencia al proteger a los bancos que ocultan las fortunas mal ganadas depositadas por los líderes de los países en desarrollo. Las empresas multinacionales y los bancos tienen que ser más transparentes en sus transacciones con los gobiernos de los países pobres. Habría que dar más prioridad a la prevención de la corrupción. Una idea, propuesta por primera vez por Michael Kremer, de la Universidad de Harvard, sería que la comunidad internacional calificara a ciertos regímenes como corruptos u "odiosos". Las empresas que negocien 
con tales regímenes se arriesgarían a perder sus derechos de devolución de los créditos si más tarde un gobierno legítimo decidiera una moratoria sobre la deuda contraído por su predecesor ilegal.

Los países ricos también pueden estimular los avances tecnológicos que sirvan a los intereses específicos de los países en desarrollo. Precisamente porque los países pobres carecen de mercados prósperos, las empresas privadas del mundo desarrollado tiene actualmente pocos incentivos para idear tecnologías adaptadas a ellos. De ahí surge un círculo vicioso: los países en desarrollo permanecen en la pobreza por sus limitadas oportunidades tecnológicas, pero estas oportunidades seguirán siendo difíciles de crear porque los países son pobres.

El sector de la sanidad proporciona un buen ejemplo del actual problema. Las empresas farmacéuticas de los países industrializados dedican el $90 \%$ de su investigación a enfermedades frecuentes en el mundo rico -y eso afecta a menos del $10 \%$ de la población global-. Existe poca investigación sobre las enfermedades endémicas de los regiones más pobres del mundo, porque esas inversiones no son rentables. Y sin embargo los países en desarrollo necesitan urgentemente medicamentos para prevenir y curar enfermedades como el SIDA, la malaria y la enfermedad del sueño. Más allá de los cuidados de la salud, los países en desarrollo también necesitan aumentar la producción de cultivos que resistan mejor el calor, la sequía y la salinización de las tierras de regadío, así como nuevas fuentes energéticas que reduzcan el ritmo de deforestación tropical.

Ya existe un precedente acerca de una investigación extranjera que permitía deshacer el desequilibrio tecnológico -la revolución verde-. La producción agrícola en el mundo en desarrollo se revolucionó por las nuevas variedades de trigo desarrolladas en el Centro Internacional del Maíz y el Trigo (CIMYT) de Norman Borlaug en México, y las nuevas variedades de arroz cultivadas en el Instituto Internacional de Investigación del Arroz, en Filipinas. Aunque el impacto de la revolución verde fue irregular, beneficiando a Asia y América Latina más que a África, el efecto agregado fue no obstante apreciable. En los años 60, el sur de Asia asistió a incrementos espectaculares en el crecimiento de la productividad como resultado de las nuevas variedades de semilla. Robert Evenson, de la Universidad de Yale, ha estimado que la rentabilidad global de la investigación sobre nuevas variedades fue superior al $40 \%$.

La comunidad internacional necesita aprender de este ejemplo, de forma que los recursos de las empresas ricas puedan ser aprovechadas para 
desarrollar tecnologías importantes para los países más pobres del mundo. Una mejora sencilla pero potente sería que los gobiernos de los países ricos se comprometieran por contrato a premiar la creación de esas nuevas tecnologías -por ejemplo, garantizando los contratos de compra-. En efecto, la comunidad internacional debería asegurar una rentabilidad financiera mínima a la investigación privada emprendida en beneficio de los países en desarrollo. El Centro para el Desarrollo Global ha ideado un plan para que este tipo de mecanismo de "compromiso previo al mercado" fomente la investigación en una vacuna contra la malaria, con un coste aproximado de 3 mil millones de dólares. Imagínense los beneficios de un fondo global de creación de tecnología de 50 mil millones de dólares, con desembolsos efectivos de fondos previstos en un plazo de 10 años o más. Esos 50 mil millones de dólares representan solamente alrededor del $5 \%$ de toda la ayuda financiera que los donantes han prometido gastar en beneficio de los pobres en la próxima década.

Por último, para lograr un gran impacto en los países en desarrollo, los negociadores comerciales deberían emplear más tiempo en mejorar la movilidad laboral a través de las fronteras -en particular de los trabajadores poco cualificados, que son típicamente los que se encuentran en lo más bajo de la pirámide -. Las actuales negociaciones de la OMC sobre movilidad laboral ("modo cuatro" en la jerga comercial) se centra solamente en la mano de obra altamente cualificada, pero aun en ella se han producido muy pocos avances. Unas mayores oportunidades para los trabajadores pobres y poco especializados para poder moverse a través de las fronteras aumentarían, más que ninguna otra cosa, tanto la eficiencia de la asignación de recursos en la economía mundial como las rentas de los ciudadanos de los países pobres.

Este hecho está basado en un sencillo principio de economía. La pérdida de eficiencia debida a los mercados nacionales segmentados (en oposición a los integrados) aumenta con la brecha en los precios de los diferentes mercados, y la pérdida es tanto mayor cuanto la brecha aumenta. Comparemos ahora la brecha en precios entre los diferentes tipos de mercados. En los mercados de bienes y de capital, las diferencias de precios ajustados a la calidad y al riesgo entre países son relativamente pequeñas -quizás no más de $50-100 \%-$. Pero en los mercados de trabajo, que soportan enormes restricciones en frontera, las brechas salariales entre trabajadores de similar cualificación son enormes -del orden de 500 a 1.000\%-. Por esa razón, incluso pequeñas relajaciones de las restricciones de visado de trabajo generan 
grandes ganancias de renta para los trabajadores procedentes de los países pobres (al igual que para la economía mundial). Lo especialmente atractivo es que las ganancias de renta van directamente a los trabajadores, mejor que a través de canales imperfectos de distribución (como en el caso del comercio de bienes) o a través de los gobiernos (caso de la ayuda).

Tomemos, por ejemplo, un esquema de visados para trabajo temporal que ascienda a no más del tres por ciento del total de fuerza de trabajo de los países ricos. Según este plan, a los trabajadores cualificados y no cualificados de los países pobres se les concedería empleo en países ricos durante un periodo de 3 a 5 años, y sería reemplazado por otra oleada de nuevos trabajadores al finalizar su periodo, regresando a sus países de origen. Un sistema así produciría fácilmente un rendimiento anual de 200 mil millones de dólares para los ciudadanos de las naciones en desarrollo. Los trabajadores regresados traerían al país mucho más que los beneficios procedentes de sus salarios solamente: experiencia, capacidad emprendedora, fondos para inversión, y una mayor ética del trabajo.

Para asegurarse de que estos beneficios se materializan, un régimen adecuado debe generar incentivos para que los trabajadores regresen a sus países de origen. Si bien las remesas pueden ser una importante fuente de ingresos para las familias pobres, raramente desencadenan o sostienen un desarrollo económico a largo plazo. Diseñar un esquema de mercado de trabajo que sea verdaderamente temporal es delicado, pero puede hacerse. $\mathrm{Al}$ contrario de los planes anteriores, deben existir claros incentivos para asegurarse la cooperación de todas las partes: trabajadores, empleados y gobiernos tanto del país anfitrión como del emisor. Una posibilidad sería retirar una parte de las ganancias de los trabajadores hasta que regresen a su país. Este esquema de ahorro forzado también serviría para garantizar que los trabajadores que regresan dispondrán de una apreciable suma de recursos para inversión. Además, se establecerían sanciones -una reducción de las cuotas de trabajadores, por ejemplo- para aquellos países con ciudadanos que no regresan. De ese modo, los gobiernos de los países de origen se verían motivados a crear un clima doméstico económico y político para que animen a su gente a regresar. Por supuesto, aun con el esquema mejor diseñado, es inevitable que la tasa de regreso no llegue al 100\%. Sin embargo, incluso con esta consideración, facilitar la movilidad laboral acarrearía ganancias significativas.

A pesar de sus obvias ventajas, un esquema de este tipo ¿es factible políticamente en los países desarrollados? Si se ha producido una liberalización 
comercial sustancial en los países ricos, no es porque haya sido de interés para los votantes, sino en gran parte, porque los beneficiarios potenciales han logrado organizarse y han forzado sus agendas. Las empresas multinacionales y las financieras no han tardado en reconocer los vínculos entre el aumento del acceso a los mercados exteriores y el aumento de sus beneficios, y se han ocupado de plantear la cuestión en el contenido de las negociaciones. A los flujos de trabajo temporal, por el contrario, les ha faltado una "base electoral" en los países desarrollados. Y ello no porque sus beneficios fueran a ser pequeños, sino porque los potenciales beneficiarios no son claramente identificables. Últimamente la marea está empezando a cambiar como consecuencia de la escasez de mano de obra en sectores como la alta tecnología y las faenas temporales agrícolas, y porque los flujos de entrada de mano de obra aumentarían la base fiscal para financiar las pensiones de los jubilados, aportando de ese modo una solución parcial a los déficits en los sistemas de pensiones de cobro inmediato ("pay-as-you-go systems"). Más aún, las realidades políticas pueden cambiar con un liderazgo adecuado. En los EEUU el presidente George W. Bush ya ha propuesto un programa de trabajo temporal, que si se diseña adecuadamente podría marcar un comienzo prometedor.

Hay, por supuesto, otras formas en que el mundo rico podría contribuir al desarrollo. Los países desarrollados podrían jugar un rol importante en la prevención y resolución de conflictos y en las crisis humanitarias de los países en desarrollo. Minimizar y eliminar el conflicto tiene beneficios obvios para la vida humana y, potencialmente, para el desarrollo a largo plazo. Igual de importante es detener la venta de armas a gobiernos peligrosos y parar el comercio de droga o el ilícito de diamantes que con frecuencia sirven para financiar a grupos delincuentes. Otra cuestión importante es la gobernanza de las instituciones económicas internacionales. El déficit democrático de estas instituciones ha causado de forma creciente un déficit equivalente de legitimidad. En la misma medida en que esta brecha reduce la efectividad de tales organizaciones, los países ricos deberían tener la prudencia necesaria para ponerse de acuerdo sobre su reforma.

\section{Nuevas prioridades}

La comunidad internacional debe preguntarse qué es lo realmente importante para el desarrollo, de forma que las buenas intenciones puedan convertirse en beneficios reales para los países más pobres. En gran medida, el 
progreso sostenible está en manos de los propios países pobres. Internalizar esta realidad es importante para el mundo en desarrollo -y también para el mundo rico-, aunque no sea sino porque haciendo eso vencerían la perenne tentación de prometer resultados que no pueden ser alcanzados.

Dicho esto, hay algo que debe quedar claro: los países desarrollados no deben abandonar a los pobres en su situación apremiante. Sin embargo, si los países ricos quieren verdaderamente ayudar a los países en desarrollo a conseguir un crecimiento duradero, deben ponerse a pensar de forma creativa sobre la agenda del desarrollo. Si la ayuda aumenta y se distribuye de forma más eficiente y las desigualdades del mercado se corrigen, entonces los dos pilares tradicionales del desarrollo darán buenos rendimientos. Pero estos rendimientos no deben ser sobrevalorados. En realidad, otras líneas de acción -tales como dar a los países pobres mayor control sobre la política económica, financiar tecnologías más apropiadas para el desarrollo, y abrir los mercados de trabajo- podrían producir beneficios más significativos. Es hora de dirigir la atención de los países más ricos del mundo hacia otras formas de ayudar a los más pobres, formas que han sido desatendidas durante demasiado tiempo. 